Cite as: André, F.J., Herrero, I., Riesgo, L., 2010. Using a modified DEA model to estimate the importance of objectives. Omega, International Journal of Management Science, vol. 38: 371-382. DOI:10.1016/j.omega.2009.10.002.

http://www.sciencedirect.com/science/article/pii/S0305048309000711

\title{
A MODIFIED DEA MODEL TO ESTIMATE THE IMPORTANCE OF OBJECTIVES WITH AN APPLICATION TO AGRICULTURAL ECONOMICS
}

\author{
Francisco J. André Inés Herrero Laura Riesgo \\ Pablo de Olavide University \\ Ctra. de Utrera, km. 1 - 41013 Sevilla, Spain
}

\begin{abstract}
This paper demonstrates a connection between Data Envelopment Analysis (DEA) and a non-interactive elicitation method to estimate the weights of objectives for decisionmakers in a multiple-attribute approach. This connection gives rise to a modified DEA model that allows us to estimate not only efficiency measures but also preference weights by radially projecting each unit onto a linear combination of the elements of the payoff matrix (which is obtained by standard multicriteria methods). For users of Multiple Attribute Decision Analysis the basic contribution of this paper is a new interpretation in terms of efficiency of the non-interactive methodology employed to estimate weights in a multicriteria approach. We also propose a modified procedure to calculate an efficient payoff matrix and a procedure to estimate weights through a radial projection rather than a distance minimisation. For DEA users, we provide a modified DEA procedure to calculate preference weights and efficiency measures that does not depend on any observations in the dataset. This methodology has been applied to an agricultural case study in Spain.
\end{abstract}

Keywords: Multicriteria; Goal Programming; DEA 
Cite as: André, F.J., Herrero, I., Riesgo, L., 2010. Using a modified DEA model to estimate the importance of objectives. Omega, International Journal of Management Science, vol. 38: 371-382. DOI:10.1016/j.omega.2009.10.002. http://www.sciencedirect.com/science/article/pii/S0305048309000711

\section{Introduction and objectives}

Several authors have pointed out some close connections between Data Envelopment Analysis (DEA) and Multicriteria Decision Making (MCDM): see Belton and Vickers (1993), Stewart (1994, 1996), Zhu (1996), Joro et al. (1998), Chen (2005), Bouyssou (1999), André (2009). Some of these authors have underlined the equivalence between the notion of 'efficiency' in DEA and MCDM (e.g. Bouyssou, 1999, p. 974, and Chen, 2005) although the two approaches are different regarding how efficiency is measured in practice. In DEA, the so-called 'efficient frontier' is built as the envelope of all the Decision Making Units (DMUs hereafter) included in the sample. Efficiency is, therefore, measured in relative terms by comparing each unit with the others in the same sample. On the contrary, in MCDM, efficiency is measured in absolute terms. That is, in a MCDM problem, the decision-maker (DM) faces a number of constraints which determine the feasible set. Therefore, by exploring the feasible set it is possible to determine which solutions are efficient or not (and hence, which DMs adopting those solutions behave efficiently), without any comparison across DMs. Translating multicriteria objectives into DEA terminology, a "max" objective can be understood as an output whereas a "min" objective can be interpreted as an input or a bad output (Doyle and Green, 1993; Steward, 1994; and Bouyssou, 1999).

We report a further connection by stressing the parallelism between DEA and the multicriteria non-interactive method proposed by Sumpsi et al. (1997) to estimate the weights of different objectives in the preferences of DMs. We claim that, although these methodologies have been developed independently of each other, there is a strong parallelism between them. The first contribution of this paper is to underline this connection between DEA and this MCDM methodology, as well as providing a new interpretation for the procedure of Sumpsi et al. in terms of efficiency.

MCDM and DEA also have in common that both of them deal with individuals, activities or organizations that are concerned with multiple objectives or inputs and outputs. In such a framework, it would appear to be relevant to measure or evaluate the relative importance of each objective, input or output according to the preferences of DMs. As we will discuss in Section 3, the methodology of Sumpsi et al. is aimed at measuring this importance by projecting the observed values of objectives onto a linear combination of 
Cite as: André, F.J., Herrero, I., Riesgo, L., 2010. Using a modified DEA model to estimate the importance of objectives. Omega, International Journal of Management Science, vol. 38: 371-382. DOI:10.1016/j.omega.2009.10.002. http://www.sciencedirect.com/science/article/pii/S0305048309000711

the elements of the payoff matrix (where such a matrix is obtained by optimizing each objective separately). We claim that, provided that all the elements of the payoff matrix are efficient, the procedure introduced by Sumpsi et al. has a strong resemblance to DEA, where each unit is projected onto a combination of efficient units. In order to guarantee that the elements of the payoff matrix are efficient we propose to construct the payoff matrix by solving an auxiliary lexicographic problem.

On the other hand, although the aim of DEA is to estimate not preferences but efficiency scores, it requires the construction of a weighted combination of inputs and outputs. As the weights (known as virtual multipliers) used to compute such combinations are endogenously determined to provide the best possible score for each unit, they could be understood as having some connection with the preferences of DMs. For example, Cooper et al. (2000, Section 6.6) suggest bounding DEA weights according to the importance given by some experts to each of the criteria (inputs) using an Analytic Hierarchy Process (AHP) analysis. However, the weights obtained from a standard DEA analysis are not a suitable measure of the preferences of a given DM, since DEA parameters are crucially influenced by the structure of the production process under analysis, which is often related to technological issues and not to the preferences of decision-makers. Moreover, the representation of the efficient frontier in DEA is critically influenced by the amounts of inputs and outputs of other observations in the dataset whereas, in principle, the preferences of an individual should not be influenced by the decisions of other individuals.

The second contribution of this paper is to establish a particular way in which to apply DEA in order to obtain estimates of preference parameters, by taking advantage of the parallelism between DEA and the Sumpsi et al. methodology. For this purpose, we propose to project radially each decision unit onto a linear combination of the (efficient) elements of the payoff matrix. The main idea is to use DEA including the elements of the payoff matrix as the only units in the reference set and to interpret the parameters associated to each reference unit (denoted as $\lambda$ ) as the weights given by the DM to each criterion or throughput. The underlying rationale of this procedure is to control for the technological constraints (those related to the production structure) and isolate the effects specifically associated with preferences. By evaluating the distance to each 
Cite as: André, F.J., Herrero, I., Riesgo, L., 2010. Using a modified DEA model to estimate the importance of objectives. Omega, International Journal of Management Science, vol. 38: 371-382. DOI:10.1016/j.omega.2009.10.002. http://www.sciencedirect.com/science/article/pii/S0305048309000711

element of the payoff matrix it can be inferred which criteria are revealed as more or less important for the DM. Using this approach, we arrive at both an estimation of the preference weights for each DM and an approximate measure of efficiency in a single model. This efficiency measure has the property of being independent of the rest of the observations in the dataset. A key advantage of using this modified DEA model rather than the methodology proposed by Sumpsi et al. is that, when using a DEA-like approach, the projected points on the efficient frontier keep the same proportion of inputs and outputs than the real observations to which they are associated. In this sense, the projected points can be seen as being more similar in their preferences to the original observations they come from.

Our methodological proposal has some resemblance with the idea introduced by Golany and Roll (1994), Cook et al. (2004) and Cook and Zhu (2005) which consists in including 'standards' into the sample of DMUs. The common feature is that we propose to use as reference units the elements of the payoff matrix, which might be seen as a particular kind of standards. Nevertheless, there are also important differences. First, from the technical point of view, our reference set consists only of the elements of the payoff matrix, whereas the aforementioned references include the standards together with the sample of observed DMUs. More importantly, the goal of both approaches is different. In Golany and Roll (1994) and Cook and Zhu (2005), the motivation to include the standards is to improve the measurement of efficiency whereas, in our case, the aim is to get preference weights estimates and (approximate) efficiency measures are obtained only as a by-product. Bougnol et al. (2010) affirmed that it is a common and unconscious practice in real world to include these standards to measure performance without formally applying a DEA model. Other authors (Ulucan and Atici, 2010), noted that in some cases the benchmarks for some units were not realistic but they used a different approach. They used some clustering techniques to improve the efficiency measures of inefficient units.

The paper has the following structure: Section 2 reviews the basic elements of the DEA approach. Section 3 presents the Sumpsi et al. methodology and proposes a modification to guarantee that all the elements of the payoff matrix are efficient. The fourth Section stresses the connections between both methodologies and, using these 
Cite as: André, F.J., Herrero, I., Riesgo, L., 2010. Using a modified DEA model to estimate the importance of objectives. Omega, International Journal of Management Science, vol. 38: 371-382. DOI:10.1016/j.omega.2009.10.002. http://www.sciencedirect.com/science/article/pii/S0305048309000711

connections, it presents an alternative way of using DEA to measure efficiency and estimate the weights of inputs and outputs. Section 5 presents an empirical application of the suggested method to agricultural economics, using real data from an irrigated area in Spain. In the light of the results, this paper not only demonstrates a connection between two different methodologies, but also proposes a model that will provide the results of the two methodologies at the same time. On the one hand, we obtain efficiency measures that are very close to the real values and to conventional DEA measures. Moreover, these efficiency measures have the advantage of being determined by the structure of the feasible set alone, and not by the other elements in the dataset. As a result, the efficiency score for each unit is robust with respect to any change in the sample. On the other hand, we also obtain preference weights that are very similar to those obtained when using the methodology of Sumpsi et al. Since, following a DEA logic, these weights are obtained from a radial projection, they have the peculiarity that the proportions among the relevant objectives in the observed data and the projection are the same. In order to test the practical usefulness of these estimates we show, in a validation exercise, that they provide a good approximation to observed behaviour. Section 6 summarizes the main contributions of the paper.

\section{DEA model}

In a standard DEA model there are $n$ DMUs, using $s$ different inputs to produce $t$ different outputs. The envelopment DEA model proposed by Banker et al. (1984) can be formulated as follows:

$$
\begin{aligned}
& \text { Max } \theta \\
& \text { s.t.: } \\
& \lambda^{T} Y \geq \theta Y_{0} \\
& \lambda^{T} X \leq X_{0} \\
& \overrightarrow{1} \lambda=1 \\
& \lambda \geq 0
\end{aligned}
$$

where $X(Y)$ is the matrix representing all the inputs (outputs) of all the DMUs, $T$ denotes transposing, $\overrightarrow{1} \equiv(1, \ldots, 1)$ and the $\lambda_{j}$ parameters $(j=1, \ldots, n)$ are the weights associated with each observed DMU in order to construct a convex combination of all of 
Cite as: André, F.J., Herrero, I., Riesgo, L., 2010. Using a modified DEA model to estimate the importance of objectives. Omega, International Journal of Management Science, vol. 38: 371-382. DOI:10.1016/j.omega.2009.10.002.

http://www.sciencedirect.com/science/article/pii/S0305048309000711

them (or just a subset if some $\lambda_{j}$ 's are equal to zero). The values of these parameters are DMU-specific.

DEA seeks to identify efficient units and combine them to construct an efficient frontier. A unit is said to be radially efficient if the optimal value of $\theta$ is equal to one. In order to guarantee that a unit is fully efficient, a second phase analysis must be carried out. In this second optimisation stage the sum of the positive and negative slacks, defined as $s^{+}=\lambda^{T} Y-\theta Y_{0}$ and $s^{-}=X_{0}-\lambda^{T} X$ respectively, is maximised. In this case, a unit is said to be fully efficient if the optimal value of $\theta$ is equal to one and all the slacks are equal to zero. The technical efficiency rate $(T E)$ is given by $T E=1 / \theta$, which is upper bounded by one and lower bounded by zero.

The peer units associated with the unit under analysis are those with a strictly positive value of $\lambda$. The combination (weighted by the $\lambda s$ ) of these peer units defines a virtual unit on the frontier that is the efficient projection of the unit under analysis.

We can also interpret DEA as minimizing the distance from the unit under analysis to the set of hyperplanes that envelopes all DMUs. This interpretation is more easily understood using the multiplier (output-oriented) model which is the dual model of the previous one. It has the following formulation:

$$
\begin{aligned}
& \text { Min } \quad v^{T} X_{0}-v_{0} \\
& \text { s.t.: } \\
& \mu^{T} Y_{0}=\overrightarrow{1} \\
& -\mu^{T} Y_{j}+v^{T} X_{j}-v_{0} \overrightarrow{1} \geq 0 \quad \forall j=1, \ldots, n \\
& \mu, v \geq \overrightarrow{0}
\end{aligned}
$$

where coefficients $\mu_{i}$ and $v_{r}$ are known as virtual multipliers.

Since the virtual multipliers $\mu_{i}$ and $v_{r}$ from $\left(\mathrm{BCC}_{\mathrm{P}}-\mathrm{O}\right)$ are endogenously determined to provide the best score for each DMU, they could be interpreted as being somehow related to the weight, or the importance, that the unit under analysis assigns to each 
Cite as: André, F.J., Herrero, I., Riesgo, L., 2010. Using a modified DEA model to estimate the importance of objectives. Omega, International Journal of Management Science, vol. 38: 371-382. DOI:10.1016/j.omega.2009.10.002. http://www.sciencedirect.com/science/article/pii/S0305048309000711

input or output in order to achieve maximum efficiency (see Cooper et al., 2000, p. 25 and pp. 169-173, Tone, 1989, 1999). Nevertheless, these coefficients cannot be interpreted as measuring the preferences of DMs, since they are basically technical parameters (Allen et al., 1997). In Section 4 we introduce an alternative way of using DEA to estimate the importance of each input and output for each DMU. The idea is to take advantage of the parallelism between DEA and the methodology of Sumpsi et al., which is summarized in the following section.

Figure 1 is a flow chart that summarizes the main steps of DEA, the procedure by Sumpsi et al. (see Section 3) and the modified DEA method that is introduced in Section 4.

\section{Estimating the weights of attributes in a multiple attribute context}

The methodology proposed by Sumpsi et al. (1997), and extended by Amador et al. (1998), is based upon weighted goal programming (GP) and enables estimates of the weight or the importance that different objectives have on the observed behaviour of DMs. The aim is to get weights estimates which are compatible, not with respondents' answers to artificial questionnaires, but rather with the behaviour that they actually display (Sumpsi et al., 1997, p. 65).

Assume that some DM has a set of $q$ "more is better" objectives ${ }^{1}$ that depend on a vector of decision variables $x$ according to the functions $f_{i}(x)(i=1, \ldots, q)$. Moreover, the DM faces a number of technical constraints which determine his feasible set, denoted as $F$. The first step is to construct the payoff matrix for these objectives. The first element of the first column of this matrix is obtained by solving the mono-criterion problem:

$$
\begin{aligned}
& \operatorname{Max} f_{1}(x) \\
& \text { s.t.: } \\
& \quad x \in F
\end{aligned}
$$

\footnotetext{
${ }^{1}$ Note that this assumption does not imply any loss of generality. A "less is better" objective can be transformed in "more is better" multiplying by -1 . If the target is to get exactly a certain value, the objective can be written as minimizing the distance (or maximizing the opposite of the distance) from the attained value to the target value, so that it can be formulated as a "less is better" (or "more is better") objective. Therefore, this formulation permits us to deal with any problem involving any of the relevant types of objectives.
} 
Cite as: André, F.J., Herrero, I., Riesgo, L., 2010. Using a modified DEA model to estimate the importance of objectives. Omega, International Journal of Management Science, vol. 38: 371-382. DOI:10.1016/j.omega.2009.10.002. http://www.sciencedirect.com/science/article/pii/S0305048309000711

The optimal value of $f_{1}(x)$, denoted as $f_{1}^{*} \equiv f_{11}$, is the first entry of the payoff matrix. To get the other entries of the first column, we substitute $\arg \max f_{1}(x)$ in $f_{i}(x)$, for $i=2, \ldots, q$. The other columns of the payoff matrix are obtained by implementing the same kind of calculations, i.e., the generic element $f_{i j}$ is obtained by maximizing $f_{j}$ and plugging $\arg \max f_{j}(x)$ into $f_{i}(x)$. For detailed information about the construction of the payoff matrix, see Ballestero and Romero (1998, pp. 11-19).

It is immediate to conclude that, if problem [1] has a unique solution, that solution is efficient; and the same statement applies for the rest of columns of the payoff matrix. Notice, however, that the payoff matrix may not be unique since the mono-criterion problems could have alternative optima, and some of them might be inefficient. To illustrate this, assume that there are two objectives and that the feasible set is represented by the polygon $O A B C D$ in Figure 2 . When optimizing objective 1 (2), we could obtain any point on segment $C D(A B)$. Since we are interested in an interpretation in terms of efficiency, it is convenient to have efficient points as a reference. In Figure 2, the set of efficient solutions is given by segment $B C$, so we should select point $C$ for the first column of the payoff matrix and B for the second column. We propose to do this by solving the following lexicographic problem for every objective $i=1, \ldots, q$ :

$$
\begin{aligned}
& \text { Lex } \max _{\text {s.t.: }}\left\{f_{i}(x), \sum_{j \neq i} \alpha_{j} f_{j}(x)\right\} \\
& \quad x \in F
\end{aligned}
$$

meaning that objective $i$ is maximized and, if some alternative optima exist, an arbitrary linear combination of the rest of objectives (with $\alpha_{j}>0$ for all $j \neq i$ ) is optimized without worsening the performance of objective $i$. For our purpose, the specific values of $\alpha_{j}$ do not matter, as long as they are positive and hence provide an efficient solution. In our application we calculate the payoff matrix using this procedure. From now on, therefore, we will assume that all the columns of the payoff matrix are efficient by construction. 
Cite as: André, F.J., Herrero, I., Riesgo, L., 2010. Using a modified DEA model to estimate the importance of objectives. Omega, International Journal of Management Science, vol. 38: 371-382. DOI:10.1016/j.omega.2009.10.002.

http://www.sciencedirect.com/science/article/pii/S0305048309000711

Now, assume that the DM facing the decision problem described above makes a decision. A researcher who does not know the DM's preferences observes his decision and, using this information, aims to elicit the weights given by the DM to each objective. Following Sumpsi et al. (1997), this elicitation can be obtained by solving the following system of $q+1$ equations:

$$
\begin{aligned}
& \sum_{j=1}^{q} w_{j} f_{i j}=f_{i} \quad i=1, \ldots, q \\
& \sum_{j=1}^{q} w_{j}=1
\end{aligned}
$$

where $f_{i j}$ is the $i j-$ th element of the payoff matrix, $f_{i}$ is the observed value of the $i-t h$ criterion and $w_{j}$ measures the weight of the $j-t h$ objective. Usually, a positive solution to system [3] does not exist and, in such a case, it is necessary to find the closest set of weights by solving the following GP problem:

$$
\begin{array}{ll}
\operatorname{Min} \sum_{i=1}^{q} \frac{n_{i}+p_{i}}{f_{i}} & \\
\text { s.t.: } & \\
\sum_{j=1}^{q} w_{j} f_{i j}+n_{i}-p_{i}=f_{i} & i=1, \ldots, q \\
w_{j} \geq 0 & i=1, \ldots, q \\
n_{i}, p_{i} \geq 0 & i=1, \ldots, q \\
\sum_{j=1}^{q} w_{j}=1 &
\end{array}
$$

where $n_{i}\left(p_{i}\right)$ is the negative (positive) deviation variable from the observed (real) value $f_{i}$ and, by definition, either $n_{i}=0$ or $p_{i}=0$ or both. When solving [4], the observed point is projected onto another point that is constructed as a weighted sum of the elements of the payoff matrix. Note that, by using the sum of the deviations, the proposal by Sumpsi et al. involves minimizing the $L_{1}$ distance ("Manhattan") from the observed point to the weighted combination of the elements of the payoff matrix. This version can be readily extended to consider any $L_{p}$ distance. As a matter of fact, in our application we will use 
Cite as: André, F.J., Herrero, I., Riesgo, L., 2010. Using a modified DEA model to estimate the importance of objectives. Omega, International Journal of Management Science, vol. 38: 371-382. DOI:10.1016/j.omega.2009.10.002. http://www.sciencedirect.com/science/article/pii/S0305048309000711

the $L_{2}$ (Euclidean) distance, implemented by minimizing the sum of the squared deviation variables, instead of the deviation variables themselves.

The first key insight of this paper is the strong parallelism of this methodology with DEA. Given that, by construction, the elements of the payoff matrix are efficient, the solution of [4] can be interpreted as projecting every observation onto a combination of efficient units. The main difference with respect to DEA is that the reference units are not "real" observed units, but potential (feasible) observations that could show up if the DM were interested in maximizing just one objective. A second difference is that, by construction, in this procedure, the approximation to the efficient frontier is linear (instead of piece-wise linear as is usual in DEA).

\section{Example 1}

Let us illustrate a problem with two decision variables $x \equiv\left(x_{1}, x_{2}\right)$ and two objectives to be maximised, $f_{1}(x), f_{2}(x)$ defined as $f_{1}(x)=x_{1}, f_{2}(x)=x_{2}$. Assume that the decision-maker is subject to the following constraints:

$$
\begin{aligned}
& x_{2}+0.2 \cdot x_{1} \leq 7 \\
& x_{2}-x_{1} \leq 4 \\
& -9 \cdot x_{2}+4 \cdot x_{1} \leq 20 \\
& x_{1}, x_{2} \geq 0
\end{aligned}
$$

The feasible set is defined by the polygon OABCD shown in Figure 3. By maximizing $f_{1}(x)$ subject to [5], we obtain the first element of the payoff matrix, $\left(f_{11}, f_{21}\right)=\mathrm{C} \equiv$ $(14.31,4.14)$ and maximizing $f_{2}(x)$ subject to [5] we obtain the second element of the payoff matrix, $\left(f_{12}, f_{22}\right)=\mathrm{B} \equiv(3.33,6.33)$. In this case, the payoff matrix is unique and we only need to solve [1] ([2] is not needed). For an observation such as z, problem [4] (Figure 3) consists of finding a point on segment BC as "close" (in a certain metric) as possible to the observed vector $z \equiv(6,4.5)$. After solving [4], using the $L_{1}$ metric for point $z$, we find that it is projected onto $E \equiv(6,5.8)$. Note that different metrics result in different projections. For example, the $L_{2}$ or Euclidean metric would result in projecting 
Cite as: André, F.J., Herrero, I., Riesgo, L., 2010. Using a modified DEA model to estimate the importance of objectives. Omega, International Journal of Management Science, vol. 38: 371-382. DOI:10.1016/j.omega.2009.10.002. http://www.sciencedirect.com/science/article/pii/S0305048309000711

point $z$ onto point $H \equiv(6.77,5.65)$. In the following section we will present a new way of projecting observation $z$ using a modified DEA model.

Another important insight is the fact that the $w_{j}$ parameters resulting from problem [4] can be understood as representing the weight of each criterion in the preferences of the DM. The interpretation is the following: if an agent faces the decision problem depicted in Figure 2, he can choose among all the feasible points in OABCD. By rationality, he should choose any point on the efficient frontier BC. By choosing one specific point and discarding all the rest, he is revealing which alternative he prefers. If the DM were concerned only about the first (second) objective, he should choose point $C(B)$ or a point very close to it. Then, the elicitation procedure should give as estimates $w_{1}=1, w_{2}=0$ $\left(w_{1}=0, w_{2}=1\right)$. In general, when objective $j$ is very important (is not very important) for the DM, the observed vector of achieved objectives should be very close (not be very close) to the $j$ 'th element of the payoff matrix and therefore $w_{j}$ should be very close to 1 (to 0 ). This method aims at measuring revealed preferences, as opposed to declared preferences which are typically obtained from direct surveys. For an application of this method to estimating preferences see, for example, Gómez-Limón and Berbel (2000) or Gómez-Limón and Riesgo (2004).

Assume again that the DM's observed decision is point $z$. Nevertheless, point $z$ itself cannot be understood as being the result of a rational decision-making process since it is inefficient. Nevertheless, once $z$ is projected onto (our approximation of) the efficient frontier, the resulting projection (in this case, point E) can be taken as a surrogate of the observed decision, i.e, that efficient point which is as close as possible to the observed one. Solving [4] we express $E$ as a linear convex combination of $B$ and $C$, which gives the estimated weights $\left(w_{1}, w_{2}\right)=(0.24,0.76)$. We take these as our elicitation for the weights of objectives 1 and 2 in the DM's preferences.

\section{Example 2}

We present now another example which is taken from an application of our methodology to agricultural economics. The whole application is developed in detail in Section 5. 
Cite as: André, F.J., Herrero, I., Riesgo, L., 2010. Using a modified DEA model to estimate the importance of objectives. Omega, International Journal of Management Science, vol. 38: 371-382. DOI:10.1016/j.omega.2009.10.002.

http://www.sciencedirect.com/science/article/pii/S0305048309000711

Assume a set of farmers, each of whom have100 hectares (ha) of land. Each farmer can decide to grow either winter cereals (1), maize (2) or beans (3). Denote as $x_{h}$ the surface devoted to the $h$-th crop $(h=1,2,3)$. We know that the farmers are concerned about three objectives: but we do not know, a priori, which is the weight of every objective. The first objective is maximising total gross margin (TGM):

$$
f_{1}=T G M=\sum_{h} G M_{h} \cdot x_{h}
$$

where $G M_{h}$ is a technical coefficient measuring the gross margin per unit of crop $h$. In our application, we have the values $\left(G M_{1}, G M_{2}, G M_{3}\right)=(407.11,964.09,918.47)$. The second objective is minimising risk $(V A R)$ :

$$
f_{2}=V A R=x^{T}[C O V] x
$$

where $x^{T} \equiv\left(x_{1}, x_{2}, x_{3}\right)$ and $[C O V]$ is the variance-covariance matrix of the gross margins obtained from different crops. In our application, we have:

$$
\text { COV }=\left[\begin{array}{ccc}
8990.80 & 16765.90 & -2440.67 \\
16765.90 & 54857.55 & -14852.81 \\
-2440.67 & -14852.81 & 170565.62
\end{array}\right]
$$

The third objective is minimising total labour input $(T L)$ :

$$
f_{3}=T L=\sum_{h} L_{h} \cdot x_{h}
$$

where $L_{h}$ represents the technical coefficient indicating labour requirements (hours per hectare) for each crop $h$. In our case, $\left(T L_{1}, T L_{2}, T L_{3}\right)=(10.6,40.9,16.40)$. For simplicity, assume that the feasible set is determined by the only constraint given by total land availability:

$$
x_{1}+x_{2}+x_{3}=100
$$

Consider now that we have a sample of four farmers and we can observe their realized values of the three objectives (which follow as a result from their crop decisions), as shown in Table 1.

In order to estimate the weights given by every farmer to each objective, we follow the procedure suggested by Sumpsi et.al. First of all, we need to calculate the payoff matrix. We do so by solving three mono-criterion problems. First, we maximize TGM subject to 
Cite as: André, F.J., Herrero, I., Riesgo, L., 2010. Using a modified DEA model to estimate the importance of objectives. Omega, International Journal of Management Science, vol. 38: 371-382. DOI:10.1016/j.omega.2009.10.002.

http://www.sciencedirect.com/science/article/pii/S0305048309000711

[6]-[9] and plugging the resulting value of $x$ into [6], [7] and [8] we get the first column of the payoff matrix. Similarly, we minimise $V A R$ and $T L$ to obtain the second and third columns of the payoff matrix. The results are shown in Table 2.

The main diagonal of the payoff matrix, called the ideal point, informs us that the maximum feasible value for TGM is equal to 1302.71 , the minimum value for VAR is 5424.57 and the minimum value for $T L$ is 9.22 . By choosing the worst value of each row we have the so-called anti-ideal point, which involves a minimum TGM of 474.89, a maximum VAR equal to 54857.55 and maximum $T L$ equal to 40.90 .

Let's compare these values with those observed in Table 1. We see that although the results of all four farmers are different, they have the common feature that TGM is reasonably close to the optimal value while both $V A R$ and $T L$ are rather displaced with respect to their optima, and this is particularly true for farmer 1. In other words, all four farmers are located rather close to the first column of the payoff matrix. Then, we can get the intuition that, a priori, TGM seems to be the most important objective for all the farmers. To confirm this intuition, we apply the estimation procedure suggested by Sumpsi et al, in this case, using the $L_{2}$ metric. For example, for farmer 1 , we solved the following optimisation problem :

$$
\begin{aligned}
& \operatorname{Min}\left(\frac{n_{1}+p_{1}}{1250.04}\right)^{2}+\left(\frac{n_{2}+p_{2}}{48000.36}\right)^{2}+\left(\frac{n_{3}+p_{3}}{40.90}\right)^{2} \\
& \text { s.t.: } \\
& 1302.71 \cdot w_{1}+486.77 \cdot w_{2}+474.89 \cdot w_{3}+n_{1}-p_{1}=1250.04 \\
& 54857.55 \cdot w_{1}+5424.57 \cdot w_{2}+5754.11 \cdot w_{3}+n_{2}-p_{2}=48000.36 \\
& 40.90 \cdot w_{1}+9.53 \cdot w_{2}+9.22 \cdot w_{3}+n_{3}-p_{3}=40.90 \\
& w_{1}, w_{2}, w_{3} \geq 0 \\
& \sum_{j=1}^{3} w_{j}=1
\end{aligned}
$$

and we did the same for all four farmers. The resulting estimated weights are displayed in Table 3. 
Cite as: André, F.J., Herrero, I., Riesgo, L., 2010. Using a modified DEA model to estimate the importance of objectives. Omega, International Journal of Management Science, vol. 38: 371-382. DOI:10.1016/j.omega.2009.10.002. http://www.sciencedirect.com/science/article/pii/S0305048309000711

Note that these values confirm our initial intuition since TGM appears to be the most important objective for all farmers and, in the case of farmer 1 it is basically the only objective that seems to matter in his decision making process.

\section{Combining methodologies: using a modified DEA model to estimate the weights associated with each throughput}

Using the parallelism between the methodologies presented in sections 2 and 3, our aim is to find a way to use DEA so that it provides a measure of preference parameters. Although DEA virtual multipliers $\mu_{i}$ and $v_{r}$ from problem $\left(\mathrm{BCC}_{\mathrm{M}^{-}} \mathrm{O}\right)$ are associated with outputs and inputs respectively, they cannot be properly interpreted as preference parameters linked to these outputs and inputs, because they are affected by the technological structure of the activity under analysis and by the values of these throughputs for the other units. To fully appreciate this point, assume a case with two outputs $\left(Y_{1}, Y_{2}\right)$ and consider a specific DMU focused on maximizing only $Y_{1}$ and not caring at all about $Y_{2}$. These preferences should be represented by a weight equal to one for $Y_{1}$ and zero for $Y_{2}\left(w_{1}=1, w_{2}=0\right)$. Nevertheless, it may well be the case that the feasible set is such that the minimum attainable value of $Y_{2}$ is strictly positive. As a consequence, we could observe that this DMU has a positive value for $Y_{2}$ and we may obtain a strictly positive value for the virtual multiplier associated with $Y_{2}$. However, this positive value should not be interpreted as a positive preference for output 2 , as it is determined by technical issues, i.e., by the shape of the feasible set.

Furthermore, in DEA, efficiency is measured in relative terms, in the sense that the efficiency score depends on the observations to which the unit under analysis is being compared, and the values of the virtual multipliers also depend on the reference set. Nevertheless, the preferences of a DM, as they are typically understood in economics and decision theory, are privately given and do not depend on the other individuals.

In order to obtain a measure of preference parameters, we suggest using a modified $\mathrm{BCC}_{\mathrm{E}}-\mathrm{O} \mathrm{DEA}$ model, with the only difference being that the reference set is not made up of all observations in the dataset, but instead comprises only the elements of the payoff 
Cite as: André, F.J., Herrero, I., Riesgo, L., 2010. Using a modified DEA model to estimate the importance of objectives. Omega, International Journal of Management Science, vol. 38: 371-382. DOI:10.1016/j.omega.2009.10.002. http://www.sciencedirect.com/science/article/pii/S0305048309000711

matrix, i.e., those extreme (virtual) units that optimize each criterion separately. We will call this a modified DEA model.

The mathematical expression of the model is the following:

$$
\begin{aligned}
& \operatorname{Max} \quad \theta \\
& \text { s.t.: } \\
& \lambda^{T} Y^{*} \geq \theta Y_{0} \\
& \lambda^{T} X^{*} \leq X_{0} \\
& \vec{I} \lambda=1 \\
& \lambda \geq 0
\end{aligned}
$$

where $Y^{*}$ is a matrix whose rows contain the value of the outputs (values of the objectives for maximising) of each of the elements in the payoff matrix. Similarly $X^{*}$ is a matrix where each row contains the values of the inputs (or criteria to be minimised) of a given unit of the payoff matrix. Therefore, both $Y^{*}$ and $X^{*}$ have the same amount of rows as the number of elements in the payoff matrix. The rest of the elements in problem [11] are the usual ones in a standard DEA model. By using this modified DEA model, the values of $\lambda$ associated with each unit of the payoff matrix have a particular meaning: they can be considered as estimates of the preference weightings assigned to each objective (input/output). To understand this claim, note that we are projecting each observation on a convex combination of the elements of the payoff matrix, so that the values of $\lambda$ represent the degree of proximity of the observed unit to each of these elements. Since the latter can be seen as virtual units associated with the maximisation (or minimisation) of each of the different objectives, following the discussion presented in Section 3 , it is natural to interpret $\lambda$ as the weight given to those objectives (or, to outputs and inputs, in DEA terminology).

The rationale behind this procedure is the following: the elements of the payoff matrix explicitly recognize that, when only one objective (or equivalently, one output or input) is optimized, each DMU may have to take a certain value of the rest of attributes for technological or feasibility reasons. When these elements are included in the reference 
Cite as: André, F.J., Herrero, I., Riesgo, L., 2010. Using a modified DEA model to estimate the importance of objectives. Omega, International Journal of Management Science, vol. 38: 371-382. DOI:10.1016/j.omega.2009.10.002. http://www.sciencedirect.com/science/article/pii/S0305048309000711

set, the resulting coefficients represent the importance that the unit under analysis gives to each of the criteria controlling for the feasibility constraints. Furthermore, as the reference elements are efficient by construction, the hyperplane connecting them can be taken as an approximation of the efficient frontier, and the distance from each DMU turns out to be an alternative (linearly approximated) efficiency measure with the property of being independent of any DMUs in the sample.

Concerning the selection of the $\mathrm{BCC}_{\mathrm{D}} \mathrm{O}$ model, choosing a suitable version of $\mathrm{DEA}$ is not a trivial task. In this case, we aim at stressing the parallelism of DEA with the Sumpsi et al. methodology. There are at least two types of model that may be applied: additive models (Charnes et al., 1985; Tone, 2001) and conventional radial models. For consistency, the former should be compared to the Sumpsi et al. model using an $L_{1}$ norm (see, e.g., point $E$ in Figure 3) while the latter should be compared to the Sumpsi et al. model using an $L_{2}$ norm, given that a radial expansion to the frontier is generally closer to an $L_{2}$ norm than to an $L_{1}$ norm (see point $H$ in Figure 3 ). In the application presented below, we preferred to use an output-oriented radial model to an additive model because, for the purposes of comparison, additive models have the disadvantage that they maximize the slack variables (i.e., they maximize the $L_{1}$ distance to the frontier, instead of minimizing this distance, as in the Sumpsi et al. methodology).

Specifically, we have chosen a BCC output-oriented DEA model because, as it is discussed in Section 5 (see also Example 2), in the preferences of most DMs, profit maximisation seems to be the key element and this appears to fit better into an outputoriented approach. Furthermore, we do not include the unit under analysis in the reference set, which resembles the super-efficiency DEA model (Andersen and Petersen, 1993). Nevertheless, our setting is slightly different in the sense that, in the modified DEA model, the reference set (payoff matrix) remains unchanged for every unit under evaluation, whereas in a standard super efficiency DEA model the reference set change from DMU to DMU. In order to guarantee that the projection of any point (originally below or above the frontier) is always a combination of the elements of the payoff matrix. This implies that inefficient units get the same score as in the standard 
Cite as: André, F.J., Herrero, I., Riesgo, L., 2010. Using a modified DEA model to estimate the importance of objectives. Omega, International Journal of Management Science, vol. 38: 371-382. DOI:10.1016/j.omega.2009.10.002.

http://www.sciencedirect.com/science/article/pii/S0305048309000711

model but efficient ones can be super-efficient ${ }^{2}$, which means that the efficient score can be larger than one.

A key problem that may appear in benchmarking DEA models is that infeasibilities may appear. However, given the reference set we have chosen, our model is always feasible by construction. As noted in Cook et al. (2004), infeasibilities arise for those units with a larger output level (or a smaller input level) than all the units in the reference set. However, in our case, this is never the case since the elements of the payoff matrix are such that the output and input levels are optimized subject to all the technical constraints and therefore, it is not possible to find any value with better (i.e., higher for output, lower for input) values than all the units in the payoff matrix.

INES, ESTO ME PARECÍA CONFUSO Y HE TRATADO DE ACLARARLO. ESPERO NO HABER METIDO LA PATA. NO OBSTANTE, ME GUSTARÍA COMENTARLO PORQUE ME ENTRA UNA DUDA.

\section{Example 1 (continued)}

We now apply the proposed methodology to Example 1 (see above). In order to project point $z$ onto the payoff matrix, we use model [11], which takes the following form:

$$
\begin{aligned}
& \operatorname{Max} \theta \\
& \text { s.t... } \\
& 14.31 \lambda_{1}+3.33 \lambda_{2} \geq 6 \theta \\
& 4.14 \lambda_{1}+6.33 \lambda_{2} \geq 4.5 \theta \\
& \lambda_{1}+\lambda_{2}=1 \\
& \lambda_{1}, \lambda_{2} \geq 0
\end{aligned}
$$

As it is shown in Figure 3, problem [12] results in projecting point $z$ on point $G$, which is a linear convex combination of $C$ and $B$ with $\lambda_{1}=0.37$ and $\lambda_{2}=0.63$. These are our estimates of the weights given by the DM to objectives 1 and 2 respectively. We also obtain $\theta=1.228$ and, therefore, our technical efficiency ratio $T E=1 / 1.228=0.814$.

\footnotetext{
${ }^{2}$ In this paper, we use the term super-efficient to name a DMU with efficiency greater than 1.
} 
Cite as: André, F.J., Herrero, I., Riesgo, L., 2010. Using a modified DEA model to estimate the importance of objectives. Omega, International Journal of Management Science, vol. 38: 371-382. DOI:10.1016/j.omega.2009.10.002. http://www.sciencedirect.com/science/article/pii/S0305048309000711

Note that with this projection the proportion of outputs of $Z$ and its projection $(G)$ remains the same

\section{Example 2 (continued)}

Example 2 is useful to stress again the difference between standard DEA and our modified DEA approach. First, note that, in this problem, we have one "more is better" objective, TGM, and two "less is better" objectives, VAR and TL. In DEA terminology, the first can be seen as an output while the second and the third can be seen as inputs.

In standard DEA, one would solve problem $\left(\mathrm{BCC}_{\mathrm{D}}-\mathrm{O}\right)$ for each $\mathrm{DMU}$ (in this case, for each farmer) taking the dataset (i.e., our sample of four farmers) as a reference. Then, $Y$ would be a vector including the value of TGM for each farmer (i.e., the first column of Table 1) while $X$ would be a matrix including the second and third columns of Table 1.

In the modified DEA model, instead of using the sample as a reference set, we use the payoff matrix (Table 2). For the first farmer, we would solve the following problem:

$$
\begin{aligned}
& \operatorname{Max} \theta \\
& \text { s.t..: } \\
& 1302.71 \lambda_{1}+486.77 \lambda_{2}+474.89 \lambda_{3} \geq 1250.04 \theta \\
& 54857.55 \lambda_{1}+5424.57 \lambda_{2}+5754.11 \lambda_{3} \leq 48000.36 \\
& 40.90 \lambda_{1}+9.53 \lambda_{2}+9.22 \lambda_{3} \leq 40.90 \\
& \lambda_{1}+\lambda_{2}+\lambda_{3}=1 \\
& \lambda_{1}, \lambda_{2}, \lambda_{3} \geq 0
\end{aligned}
$$

and doing similar calculations for all the farmers, we obtain the set of weights displayed in Table 4. We can observe that the weights when using both procedures differ to a certain extent but they are relatively similar. In the application displayed in Section 5 we show a more systematic statistical comparison between the estimated weights using both methods.

\section{Comparing methodologies}

The flow chart in Figure 1 summarizes the main steps of DEA, the procedure introduced by Sumpsi et al. and our modified DEA method. Figure 4 illustrates the similarities and 
Cite as: André, F.J., Herrero, I., Riesgo, L., 2010. Using a modified DEA model to estimate the importance of objectives. Omega, International Journal of Management Science, vol. 38: 371-382. DOI:10.1016/j.omega.2009.10.002. http://www.sciencedirect.com/science/article/pii/S0305048309000711

differences in the results obtained using all three methodologies. In standard DEA, the reference set contains all the observed DMUs (represented by black dots). The efficient frontier is constructed as the envelope of all these units (in Figure 4, FDJEI), and the efficiency of each unit is measured as the distance from it to the frontier when radially projected. In the Sumpsi et al. methodology the reference set consists only of the elements of the payoff matrix, which in Figure 4 correspond to points $A$ and $B$ (marked with a star) and the goal is to find a linear convex combination of these elements as close as possible to the observed units according to some metric (in the figure, we illustrate the $\mathrm{L}_{2}$ metric). We propose a combination of the two methods by taking the payoff matrix as the reference set and projecting each unit radially onto it. For example, unit $C$ is projected onto point C" when using the Sumpsi et al. methodology and onto point C' when using the modified DEA method (which, in this particular case, by coincidence, equals the standard DEA projection). A similar exercise is carried out for point $E$. Since $E$ is efficient, it is projected on itself when using DEA, onto $E$ " when using the method developed by Sumpsi et al. and onto E' when using the modified DEA method.

Compare, first, the results for modified DEA and Sumpsi et al. methods. In some cases, such as point $D$, both projections are virtually the same but in others (e.g. point $E$ ) there are some differences due to the different projection criteria used in both approaches: in the case of Sumpsi et al. it consists of minimizing the distance, whereas by following DEA the projection aims at keeping the proportions of outputs unchanged. In fact, the application in the case study shows very similar preference parameters with both approaches.

Using the modified DEA approach, we also obtain an efficiency measure as the distance from each unit to the new frontier $A B$, so that we can compare this measure to standard DEA. For example, the efficiency score for point $C$ is the same in a standard DEA approach and in the modified DEA method (being inefficient in both cases). Units $D$ and $E$, which appear to be efficient in a standard DEA method, appear to be super-efficient in the modified DEA method. Nevertheless, in the application presented below it is shown that, although the numerical value of the efficiency scores can be different for standard and modified DEA models, the rankings of units tend to be rather similar. 
Cite as: André, F.J., Herrero, I., Riesgo, L., 2010. Using a modified DEA model to estimate the importance of objectives. Omega, International Journal of Management Science, vol. 38: 371-382. DOI:10.1016/j.omega.2009.10.002. http://www.sciencedirect.com/science/article/pii/S0305048309000711

Table 5 presents a summary of the key features of the three methods. The first second and third columns display the information requirements for each method. All three procedures require information about inputs and outputs (objectives in MCDM terminology) for the DMU under analysis (DM in MCDM terminology). In standard DEA this information is required not only for the DMU under analysis, but for all the DMUs of the sample. Concerning information requirements, the modified DEA method is equivalent to the one described by Sumpsi et al. in the sense that it does not require any sample but it needs the payoff matrix, which in turn requires information about the structure of the decision problem, i.e., the relevant objectives, decision variables, and the constraints faced by the DM.

The fourth and fifth columns display the information provided as an output by each method. In this respect, DEA is basically aimed at providing just efficiency measures whereas the Sumpsi et al. methodology only provides preference weighting parameters. In this respect, the modified DEA approach amounts to a combination of both methods by providing both pieces of information.

Finally, the last column underlines the criterion that is used to project each unit on the frontier. In the Sumpsi et al. method the projection is done by minimizing the distance from the observed point to its projection. The modified DEA method follows the usual spirit of DEA by using a radial projection.

\section{Application to agricultural economics and a case study}

We present now a real application in which we pursue two objectives. First, apart from the theoretical comparison that we have done among the three methodologies we are dealing with, we would like to make a statistical comparison with a real sample. Second, we aim at checking our methodology with real data to have a taste about how useful it could be in practice. For this purpose, we include a validation exercise to test how accurately our estimated weights can reproduce observed behaviour. A simplified version of this application was used to build Example 2 above. 
Cite as: André, F.J., Herrero, I., Riesgo, L., 2010. Using a modified DEA model to estimate the importance of objectives. Omega, International Journal of Management Science, vol. 38: 371-382. DOI:10.1016/j.omega.2009.10.002. http://www.sciencedirect.com/science/article/pii/S0305048309000711

\subsection{Framework}

Several authors have pointed out that, contrary to the usual assumption in conventional economics, farmers are not only concerned with the maximisation of profit, but also with other attributes such as risk, management complexity, leisure time, indebtedness, etc. See Gasson (1973), Smith and Capstick (1976), Cary and Holmes (1982). More recently, Willock et al. (1999), and Solano et al. (2001) have also stressed this point.

Since farmers make their decisions trying to simultaneously optimize a range of conflicting objectives, we analyzed the behaviour of farmers under the MCDM paradigm. Specifically, we used the theoretical framework of multiattribute utility theory (MAUT). As pointed out by Herath (1981) and Hardaker et al. (1997, p. 162), the main drawback of this approach comes from the elicitation of the multiattribute utility function (MAUF), including the mathematical shape of utility functions and the estimation of the weights of each attribute. Concerning the former issue, we assume an additive and linear MAUF. For a justification of this assumption, as well as its limitations, Gómez-Limón et al. (2003) and Gómez-Limón and Riesgo (2004) can be consulted. The resulting expression for the MAUF is:

$$
U=\sum_{j=1}^{q} \frac{w_{j}}{k_{j}} f_{j}(x)
$$

where $U$ is the utility obtained by the DM, $f_{j}$ is the value of attribute $j, k_{j}$ is a normalizing factor (usually the observed value of each attribute $j$ ), $w_{j}$ is the weight of attribute $j$, and $x$ is the vector of decision variables.

Weights for different objectives are widely used in MCDM but there is some vagueness about exactly how these weights should be interpreted. Using the MAUT approach gives us a precise interpretation for these weights as the marginal utility of each (normalized) attribute. More details about the MAUT approach can be found in Keeney and Raiffa (1976), Edwards (1977), Farmer (1987), Amador et al. (1998), Ballestero and Romero (1998), and Huirne and Hardaker (1998). 
Cite as: André, F.J., Herrero, I., Riesgo, L., 2010. Using a modified DEA model to estimate the importance of objectives. Omega, International Journal of Management Science, vol. 38: 371-382. DOI:10.1016/j.omega.2009.10.002. http://www.sciencedirect.com/science/article/pii/S0305048309000711

Concerning the estimation procedure, we are interested in comparing the modified DEA approach suggested above with the Sumpsi et al. methodology, which has been successfully checked in a number of studies, such as Berbel and Rodríguez (1998), Arriaza et al. (2002), and Gómez-Limón and Riesgo (2004) ${ }^{3}$

\subsection{Case study and dataset}

The case study is a sample of 61 farmers from the community of irrigators "Canal General del Páramo" in northern Spain. This area has 15,554 irrigated hectares (ha), divided among 5,950 landowners. It has a "mild Mediterranean" climate, $800 \mathrm{~m}$ above sea level, with long, cold winters and hot, dry summers. Rain falls mostly in spring and autumn. In decreasing order of importance, the normal crop mix is maize, winter cereals, beans and set-aside. All the data to feed the models were obtained both from official statistics and from a survey developed in the area under study during the 2000-01 agricultural year. For more information about the survey see Gómez-Limón and Riesgo (2004). In order to simulate the decision-making process of farmers under the MAUT framework, we constructed a mathematical model whereby farmers decide the value of certain decision variables, being limited by certain constraints, in order to optimize various objectives:

Decision variables. Each farmer has a vector $x \equiv\left(x_{1}, \ldots, x_{4}\right)^{T}$ of decision variables that determine his crop distribution. Variable $x_{h}(h=1, \ldots, 4)$ measures the amount of land devoted to each crop, $h$, including winter cereals, maize, beans and set-aside. To get a normalized solution, we assumed that total land size of a farm is 100 ha.

Constraints. We identify the following constraints as applied to each farmer:

- Land constraint. The sum of all crops must be equal to the total surface available to each farmer, which is normalized to 100 ha:

$$
\sum_{h=1}^{4} x_{h}=100
$$

\footnotetext{
${ }^{3}$ André and Riesgo (2007) and Andre (2008) present a methodology, partly inspired in the idea suggested by Sumpsi et al., to estimate the parameters of a nonlinear multiattribute utility function.
} 
Cite as: André, F.J., Herrero, I., Riesgo, L., 2010. Using a modified DEA model to estimate the importance of objectives. Omega, International Journal of Management Science, vol. 38: 371-382. DOI:10.1016/j.omega.2009.10.002. http://www.sciencedirect.com/science/article/pii/S0305048309000711

- Common Agricultural Policy (CAP) constraints. In order to fulfil the CAP requirements, we included $20 \%$ of set-aside for cereal, oilseed and protein crops. Any land devoted to set-aside greater than this percentage is excluded from EU subsidies, and this is taken as an invalid option in the model:

$$
\text { Maximum set aside: } x_{4} \leq 20 \% \cdot\left(x_{1}+x_{2}\right)
$$

- Rotational constraints. These were taken into account according to the criteria revealed by the farmers in the survey. For rotational conditions, farmers do not usually crop winter cereals in two consecutive years on the same soil. To represent this constraint we assume that the maximum area devoted to winter cereals in any given year is half the total surface available:

$$
x_{1} \leq 50
$$

Objectives. After the survey carried out in the area under study, we concluded that farmers take the following objectives into account:

- Maximisation of total gross margin (TGM), as a proxy of profit since, in the short run, the availability of structural productive factors (land, machinery, etc.) cannot be changed and the financial viability of farms basically depends on gross margin. TGM data were obtained from the average crop margins in a time series of seven years (1993/1994 to 1999/2000) in constant 2000 euros. The analytical expression for TGM is given in [6]

- Minimisation of risk (VAR). As noted by several authors (Just, 1974; Young, 1979; Gómez-Limón et al., 2003), farmers typically have a marked aversion to risk, so that risk is an important factor in agricultural activity. Following the classical Markowitz (1952) approach, risk is measured by the variance of $T G M$ as shown in equation [7]. The variance-covariance matrix of the gross margins obtained from different crops, was calculated from statistical data collected during a seven-year period. This classical approach has also been used in some recent works such as Bazzani (2005), Francisco and Ali (2006) and Gómez-Limón and Martínez (2006).

Minimisation of total labour input (TL), calculated according to equation [8]. This objective implies not only a cost reduction, but also an increase in leisure time and the reduction of managerial involvement, since labour-intensive crops require more technical supervision. 
Cite as: André, F.J., Herrero, I., Riesgo, L., 2010. Using a modified DEA model to estimate the importance of objectives. Omega, International Journal of Management Science, vol. 38: 371-382. DOI:10.1016/j.omega.2009.10.002. http://www.sciencedirect.com/science/article/pii/S0305048309000711

To translate these objectives into DEA terminology, note that a "max" objective can be understood as an output (with the exception of "bad outputs") whereas a "min" objective can be interpreted as an input or a bad output. There are several ways to deal with bad or undesirable outputs (see for example Scheel, 2001). In this application, we use an output-oriented DEA model where the criterion to be maximized (gross margin) is considered to be the only output and the criteria to be minimized are treated as inputs (see Doyle and Green, 1993; Steward, 1994; and Bouyssou, 1999).

Using observed values of the crop distribution for every farmer, and the relevant technical coefficients (see equations [6] to [8]), we can compute the expected values for the objectives. Moreover, we introduced an artificial inefficiency component in the data in order to test the ability of the model to measure efficiency by comparing the real (artificially introduced) efficiency rate with the estimated efficiency. We randomly generated 61 values $\xi_{\mathrm{i}}(i=1, \ldots, 61)$ from a normal distribution with mean 0.95 and standard error 0.10 , and we multiplied the TGM of each farmer by the truncated version $\overline{\xi_{i}}=\min \left\{\xi_{i}, 1\right\}$, so that we associated with each observation an efficiency score equal to the resulting (truncated) random number, with an average efficiency 0.913 and standard error 0.085 .

\subsection{Results}

We first compare the estimated preference parameters using both the Sumpsi et al. methodology (with Euclidean metric) and the modified DEA approach. Using the Sumpsi et al. approach, total gross margin $(T G M)$ turns out to have a weight, $w_{1}$, greater than 0.5 for approximately $82 \%$ of the farmers, while $w_{1}>0.9$ for some $12 \%$ of them. For risk $(V A R)$, the percentages are $18 \%$ and $0 \%$, respectively. Total labour $(T L)$ appears as a relevant objective for only $16 \%$ of the sample.

When estimating the weights $(\lambda)$ with the modified DEA method, we also obtain that TGM is the most important objective $\left(\lambda_{1}>0.5\right)$ for $82 \%$ of farmers, while for $27 \%$ of the sample, the weight of this objective is $\lambda_{1}>0.9$. In the case of $V A R$, we observe that 
Cite as: André, F.J., Herrero, I., Riesgo, L., 2010. Using a modified DEA model to estimate the importance of objectives. Omega, International Journal of Management Science, vol. 38: 371-382. DOI:10.1016/j.omega.2009.10.002. http://www.sciencedirect.com/science/article/pii/S0305048309000711

$18 \%$ of farmers assign this objective a weight greater than 0.5 . Finally, with respect to $T L$, none of farmers seem to regard total labour minimisation as a relevant objective.

Figures 5 and 6 show the cumulative distribution function of weights and Table 6 shows some descriptive statistics. We can see that the results from both approaches are very close. The correlation coefficient between weights using both methodologies is $98.5 \%$ for $T G M$ and $97.6 \%$ for $V A R$. With regard to $T L$, the weights are zero or very close to zero for most of the farmers, using any of the methods. Table 2 also shows the average differences between the weights calculated by both methodologies: 0.05 for $T G M, 0.03$ for $V A R$ and 0.03 for $T L$. We conclude that the elicitation of farmers' preferences using Sumpsi et al. or the modified DEA version is virtually identical in this exercise.

In order to test the accuracy of these estimates, we performed the following validation exercise: substituting the estimated weights (we used those obtained from the modified DEA model although, in this case, the results are virtually the same when using Sumpsi et al.) and the mathematical expressions of the attributes in [13], we simulated the behaviour of farmers by maximizing farmers' utility subject to the constraints. Then, we compared the simulated values of both the decision variables and the objectives with those in the real observed situation, as is usually done in validation exercises (see, for example, Qureshi et al., 1999). As Table 7 shows, the deviation between the average values for the objectives and the decision variables is small enough to permit us to regard the estimation model as a good approximation to the actual decision-making process.

Table 8 displays the results on efficiency measures. The modified DEA model provides a set of efficiency scores with mean 0.95 and standard error 0.075 , so the DMUs appear to be slightly more efficient with our method than with the artificial inefficiency values or standard DEA scores. This small difference can be understood as the effect of using a linear approximation to the efficient frontier. Nevertheless, the scores from the modified DEA model turn out to be highly correlated $(0.83)$ with the real inefficiency values and to those generated with standard DEA (0.83), so they seem to provide an acceptable measure of inefficiency, with the additional advantage of being independent of the set of DMUs in the sample. 
Cite as: André, F.J., Herrero, I., Riesgo, L., 2010. Using a modified DEA model to estimate the importance of objectives. Omega, International Journal of Management Science, vol. 38: 371-382. DOI:10.1016/j.omega.2009.10.002. http://www.sciencedirect.com/science/article/pii/S0305048309000711

\section{Conclusions}

This paper reports a further link between DEA and MCDM in addition to those previously reported in the literature. Specifically, we have pointed out the parallelism between DEA and the MCDM methodology proposed by Sumpsi et al. (1997) to estimate the weights of different objectives for the DMs. Moreover, we have exploited this connection in order to suggest a modified version of DEA to measure preference weights. The main idea is to use DEA, including the elements of the payoff matrix, as the only units in the reference set and interpret the $\lambda$ parameters as the weights of each criterion or throughput. We have illustrated the suggested approach by means of an application to agricultural economics. Our results show that the weights provided by the Sumpsi et al. methodology and the modified DEA model appear to be virtually identical and to provide a good approximation to the actual decision-making processes of the individuals in the sample. Moreover, the inefficiency measures provided by the modified DEA method turn out to be very close to the real values artificially introduced in the data, and also very close to the results obtained from a standard DEA approach.

Taking into account the summary presented in Table 5, we can clarify the practical contribution of our method for MCDM and DEA users. For the former we have shown a new way of understanding the method suggested by Sumpsi et al. (1997) in terms of efficiency: the projected point can be seen as a combination of efficient units. Moreover, we have proposed a modified procedure to calculate the payoff matrix to guarantee that all its elements are efficient. Finally, we propose to estimate the weights by making a radial projection rather than minimizing the distance to the payoff matrix. This procedure has the property of keeping the objectives ratio unchanged, which, in certain situations, could provide a better approximation to the true preferences. For DEA users, we have provided a modified DEA procedure which allows preference weights to be calculated. Moreover, we provide an approximate measure of efficiency that depends only on the information related to each $\mathrm{DMU}$, being independent of the remainder of the units in the sample. The main drawback of the modified DEA model for DEA users is the calculation of the payoff matrix, which usually requires full information about the decision problem that is faced by the DMU's. 
Cite as: André, F.J., Herrero, I., Riesgo, L., 2010. Using a modified DEA model to estimate the importance of objectives. Omega, International Journal of Management Science, vol. 38: 371-382. DOI:10.1016/j.omega.2009.10.002.

http://www.sciencedirect.com/science/article/pii/S0305048309000711

\section{Acknowledgements}

We thank Carlos Romero, E. Thanassoulis, Victor Podinovski, Diego Prior, one anonymous referee and the editors of Omega for useful comments. We also gratefully acknowledge financial support from the European Commission (research project EFIMAS, Proposal no. 502516) and the Spanish Ministry of Education and Science (research project SEJ2006-08416/ECON) F.J. André also thanks project SEJ200505085/ECON. We are also grateful to Hugh M. Allen for his linguistic revision of the text. 
Cite as: André, F.J., Herrero, I., Riesgo, L., 2010. Using a modified DEA model to estimate the importance of objectives. Omega, International Journal of Management Science, vol. 38: 371-382. DOI:10.1016/j.omega.2009.10.002.

http://www.sciencedirect.com/science/article/pii/S0305048309000711

\section{References}

Allen R, Athanassopoulos A, Dyson R G, Thanassoulis E. (1997) Weight restrictions and value judgements in Data Envelopment Analysis: evolution, development and future directions. Annals of Operational Research, 73, 13-34.

Amador F, Sumpsi J M, Romero C. (1998) A non-interactive methodology to assess farmers' utility functions: an application to large farms in Andalusia, Spain. European Review of Agricultural Economics, 25, 92-109.

Andersen P, Petersen NC. (1993) A procedure for ranking efficient units in DEA. Management Science, 39, 1261-1264.

Andre F. (2009) Indirect elicitation of non-linear multi-attribute utility functions. A dual procedure combined with DEA. Omega, 37, 883-895.

André F J, Riesgo L. (2007) A non-interactive method to elicit non-linear multiattribute utility functions. Theory and Application to Agricultural Economics. European Journal of Operational Research, 181, 793-807.

Arriaza M, Gómez-Limón J A, Upton M. (2002) Local water markets for irrigation in Southern Spain: A multicriteria approach. Australian Journal of Agricultural and Resource Economics, 46, 21-43.

Ballestero E, Romero C. (1998) Multiple-criteria decision-making and its applications to economic problems. Kluwer Academic Publishers: Boston.

Banker R D, Charnes A, Cooper W W. (1984) Some models for estimating technical and scale inefficiencies in DEA. Management Science, 30, 1078-1092.

Bazzani G M. (2005) An integrated decision support system for irrigation and water policy design: DSIRR. Environmental Modelling Software, 20, 153-163.

Belton V, Vickers S. (1993) Demystifying DEA. A Visual Interactive Approach Based on Multiple Criteria Analysis. Journal of Operational Research Society, 44, 883-896.

Berbel J, Rodríguez A. (1998) An MCDM approach to production analysis: An application to irrigated farms in Southern Spain. European Journal of Operational Research, 107, 108-118.

Bougnol, M L, Duláb, J H., Estellita Linsc, M P, Moreira da Silva, A C. (2010) Enhancing standard performance practices with DEA. Omega 38, 33-45.

Bouyssou D. (1999) Using DEA as a tool for MCDM: some remarks. Journal of Operational Research Society 50, 974-978. 
Cite as: André, F.J., Herrero, I., Riesgo, L., 2010. Using a modified DEA model to estimate the importance of objectives. Omega, International Journal of Management Science, vol. 38: 371-382. DOI:10.1016/j.omega.2009.10.002.

http://www.sciencedirect.com/science/article/pii/S0305048309000711

Cary J W, Holmes W E. (1982) Relationships among farmers' goals and farm adjustment strategies: some empirics of a multidimensional approach. Australian Journal of Agricultural Economics, 26, 114-130.

Charnes A, Cooper W W, Golany B, Seiford L, Stutz J. (1985) Foundations of data envelopment analysis for Pareto-Koopmans efficient empirical production functions. Journal of Econometrics, 30, 91-107.

Charnes A, Cooper W W, Rhodes E. (1978) Measuring the efficiency of decision-making units. European Journal of Operational Research, 2, 429-444.

Chen $Y$ (2005) On preference structure in Data Envelopment Analysis. International Journal of Information Technology and Decision Making, 4(3), 411-131.

Cook W D, Seiford L M, Zhu J. (2004) Models for performance benchmarking: measuring the effect of e-business activities on banking performance. Omega, 32, 313-322.

Cook W D, Zhu J. (2005) Building performance standards into data envelopment analysis structures. IIE Transactions, 37, 267-275.

Cooper W W, Seiford L M, Tone K. (2000) Data Envelopment Analysis. A comprehensive text with models, applications, references and DEA-Solver Software. Kluwer Academic Publishers: Boston.

Doyle J, Green R. (1993) Data Envelopment Analysis and multiple-criteria decisionmaking. Omega, 21, 713-715.

Edwards W. (1977) Use of multiattribute utility measurement for social decision-making. In Bell DE, Keeney RL and Raiffa H (Eds) Decisions. John Wiley \& Sons: Chichester.

Farmer P C. (1987) Testing the robustness of multiattribute utility theory in an applied setting. Decision Sciences, 18, 178-193.

Francisco S R, Ali M. (2006) Resource allocation tradeoffs in Manila's peri-urban vegetable production systems: An application of multiple objective programming. Agricultural Systems, 87, 147-168.

Gasson R. (1973) Goals and values of farmers. Journal of Agricultural Economics, 24, 521-537.

Golany B, Roll Y (1994) Incorporating standards via data envelopment analysis. In Charnes A, Cooper WW, Lewin A Y, Seiford L M (Eds) Data Envelopment Analysis: Theory, methodology and applications, Kluwer: Boston, MA, pp. 313328. 
Cite as: André, F.J., Herrero, I., Riesgo, L., 2010. Using a modified DEA model to estimate the importance of objectives. Omega, International Journal of Management Science, vol. 38: 371-382. DOI:10.1016/j.omega.2009.10.002.

http://www.sciencedirect.com/science/article/pii/S0305048309000711

Gómez-Limón J A, Arriaza M, Riesgo L. (2003) A MCDM analysis of agricultural risk aversion. European Journal of Operational Research, 151, 569-585.

Gómez-Limón J A, Martínez Y. (2006) Multi-criteria modelling of irrigation water market at basin level: A Spanish case study. European Journal of Operational Research, 173, 313-336.

Gómez-Limón J A, Berbel J. (2000) Multicriteria analysis of derived water demand functions: a Spanish case study. Agricultural Systems, 63(1), 49-72.

Gómez-Limón J A, Riesgo L. (2004) Water pricing: Analysis of differential impacts on heterogeneous farmers. Water Resources Research, 40; Art. No. W07S05.

Hardaker J B, Huirne R B M, Anderson J R. (1997) Coping with risk in agriculture. CAB International: Oxon, UK.

Herath H M G. (1981) An empirical evaluation of multiattribute utility theory in peasant agriculture. Oxford Agrarian Studies, 10, 240-254.

Huirne R B M, Hardaker J B. (1998) A multi-attribute model to optimize sow replacement decisions. European Review of Agricultural Economics, 25, 488-505.

Joro T, Korhonen P, Wallenius J. (1998) Structural Comparison of Data Envelopment Analysis and Multiple Objective Linear Programming. Management Science, 44, 962-970.

Just R E. (1974) An investigation of the importance of risk in farmers' decisions. American Journal of Agricultural Economics, 56, 14-25.

Keeney R L, Raiffa H. (1976) Decisions with Multiple Objectives: Preferences and Value Trade-Offs. John Wiley \& Sons: New York.

Markowitz H. (1952) Portfolio selection. Journal of Finance 7, 77-91.

Qureshi M E, Harrison S R, Wegener M K. (1999) Validation of multicriteria analysis models. Agricultural Systems, 62, 105-116.

Rosen D, Schaffnit C, Paradi C J. (1998) Marginal rates and two-dimensional level curves in DEA. Journal of Productivity Analysis, 9, 205-238.

Scheel H. (2001) Undesirable Outputs in Efficiency Valuations. European Journal of Operational Research, 132, 400-410.

Smith B, Capstick D F. (1976) Establishing priorities among multiple management goals. Southern Journal of Agricultural Economics, 2, 37-43.

Solano C, León H, Pérez E, Herrero M. (2001) Characterising objective profiles of Costa Rican dairy farmers. Agricultural Systems, 67, 153-179. 
Cite as: André, F.J., Herrero, I., Riesgo, L., 2010. Using a modified DEA model to estimate the importance of objectives. Omega, International Journal of Management Science, vol. 38: 371-382. DOI:10.1016/j.omega.2009.10.002.

http://www.sciencedirect.com/science/article/pii/S0305048309000711

Steward T J. (1994) Data Envelopment Analysis and multiple-criteria decision-making: a response. Omega, 22, 205-206.

Steward T J. (1996) Relationships between Data Envelopment Analysis and Multicriteria Decision Analysis. Journal of Operational Research Society, 47, 654-665.

Sumpsi J M, Amador F, Romero C. (1997) On Farmers' Objectives: A Multi-Criteria Approach. European Journal of Operational Research, 96, 64-71.

Tone K. (1989) A Comparative Study on AHP and DEA. International Journal of Policy Information, 13, 57-63.

Tone K. (1999) A Consensus Making Method for Group Decisions. Proposals at the Committee Meeting, National Land Agency: Japan.

Tone K. (2001) A slacks-based measure of efficiency in data envelopment analysis. European Journal of Operational Research, 130, 498-509.

Ulucan, A, Atici, K B. (2010) Efficiency evaluations with context-dependent and measurespecific data envelopment approaches: An application in a World Bank supported project. Omega, 38, 68-83.

Willock J, Deary I J, Edwards-Jones G, Gibson G J, McGregor M J, Sutherland A, Dent J B, Morgan O, Grieve R. (1999) The role of attitudes and objectives in farmer decision making: business and environmentally-oriented behaviour in Scotland. Journal of Agricultural Economics, 50, 286-303.

Young D L. (1979) Risk preferences of agricultural producers: their use in extension and research. American Journal of Agricultural Economics, 61, 1063-1070.

Zhu J. (1996) DEA/AR analysis of the 1988-1989 performance of the Nanjing Textiles Corporation. Annals of Operational Research, 66, 311-335. 
Cite as: André, F.J., Herrero, I., Riesgo, L., 2010. Using a modified DEA model to estimate the importance of objectives. Omega, International Journal of Management Science, vol. 38: 371-382. DOI:10.1016/j.omega.2009.10.002.

http://www.sciencedirect.com/science/article/pii/S0305048309000711

\section{FIGURES}

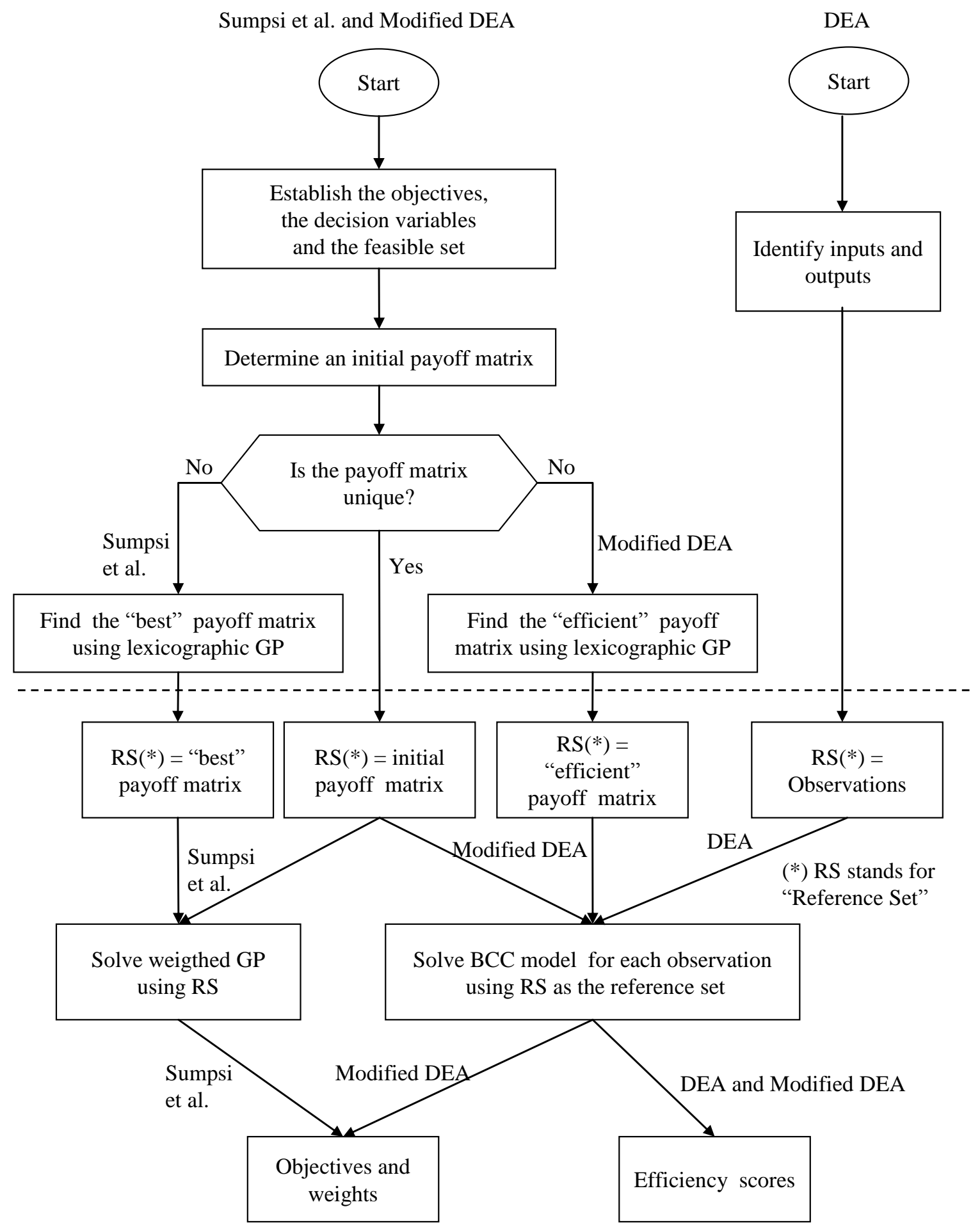

Figure 1. Main steps of analysed methodologies 
Cite as: André, F.J., Herrero, I., Riesgo, L., 2010. Using a modified DEA model to estimate the importance of objectives. Omega, International Journal of Management Science, vol. 38: 371-382. DOI:10.1016/j.omega.2009.10.002.

http://www.sciencedirect.com/science/article/pii/S0305048309000711

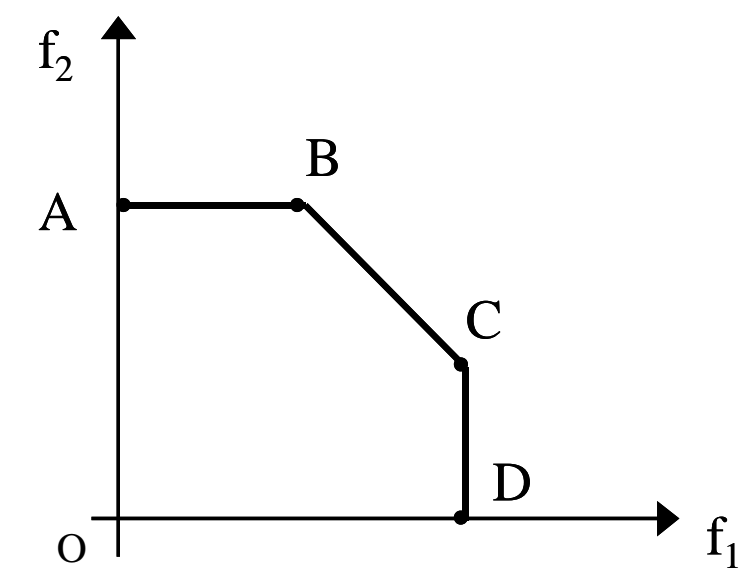

Figure 2. Example of feasible set

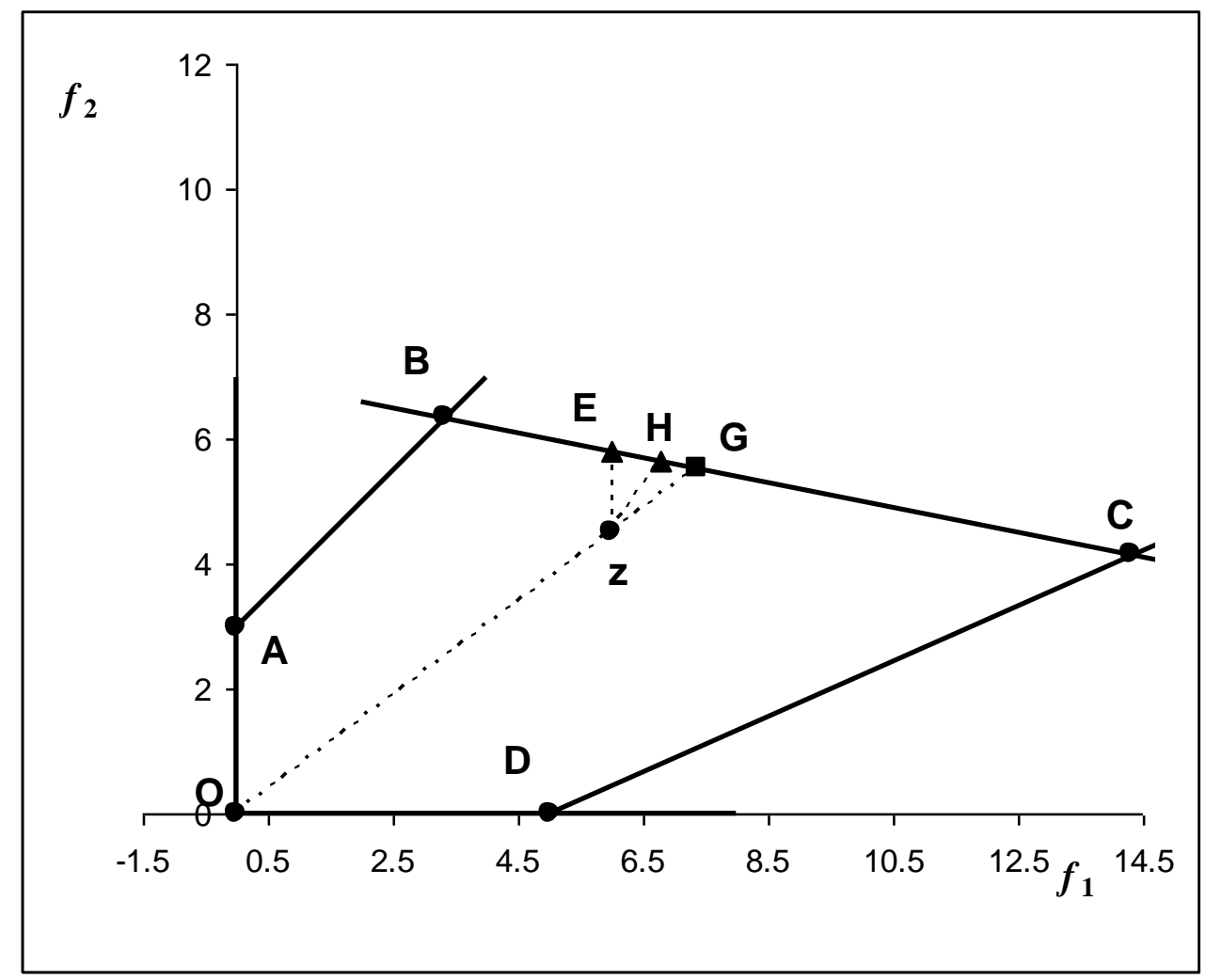

Figure 3. Geometric interpretation of problems [4] and [5]. Example 1. 
Cite as: André, F.J., Herrero, I., Riesgo, L., 2010. Using a modified DEA model to estimate the importance of objectives. Omega, International Journal of Management Science, vol. 38: 371-382. DOI:10.1016/j.omega.2009.10.002.

http://www.sciencedirect.com/science/article/pii/S0305048309000711

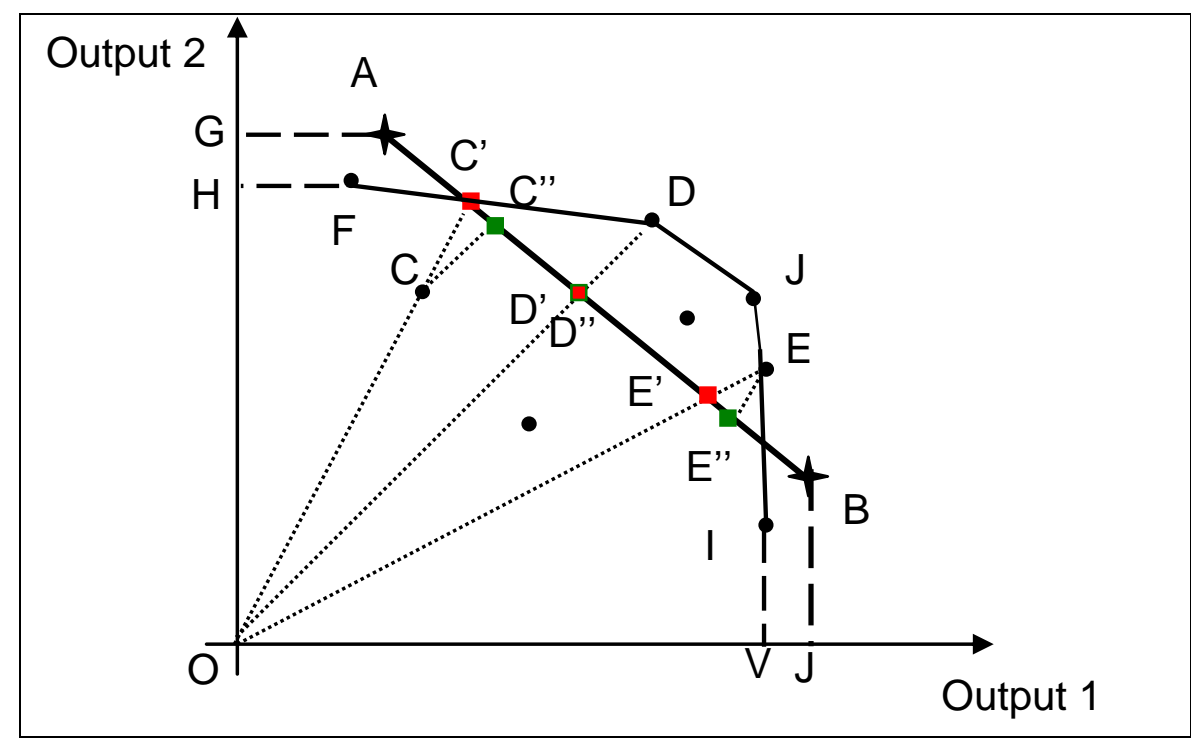

Figure 4. Comparing Sumpsi et al., DEA and modified DEA methods

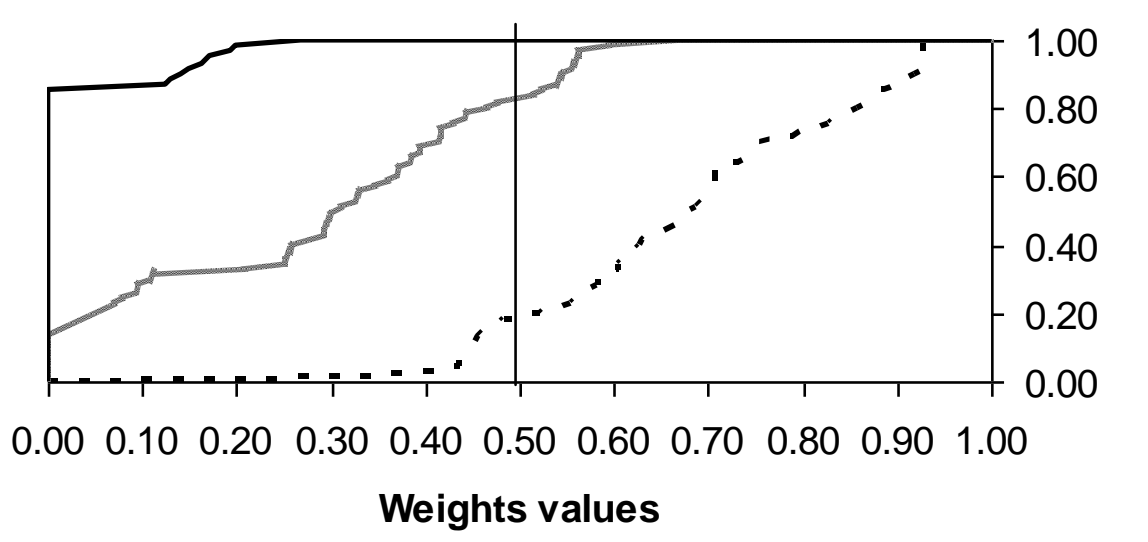

Figure 5. Probability distributions of the weights $\left(w_{i}\right)$ using Sumpsi et al. approach 
Cite as: André, F.J., Herrero, I., Riesgo, L., 2010. Using a modified DEA model to estimate the importance of objectives. Omega, International Journal of Management Science, vol. 38: 371-382. DOI:10.1016/j.omega.2009.10.002.

http://www.sciencedirect.com/science/article/pii/S0305048309000711

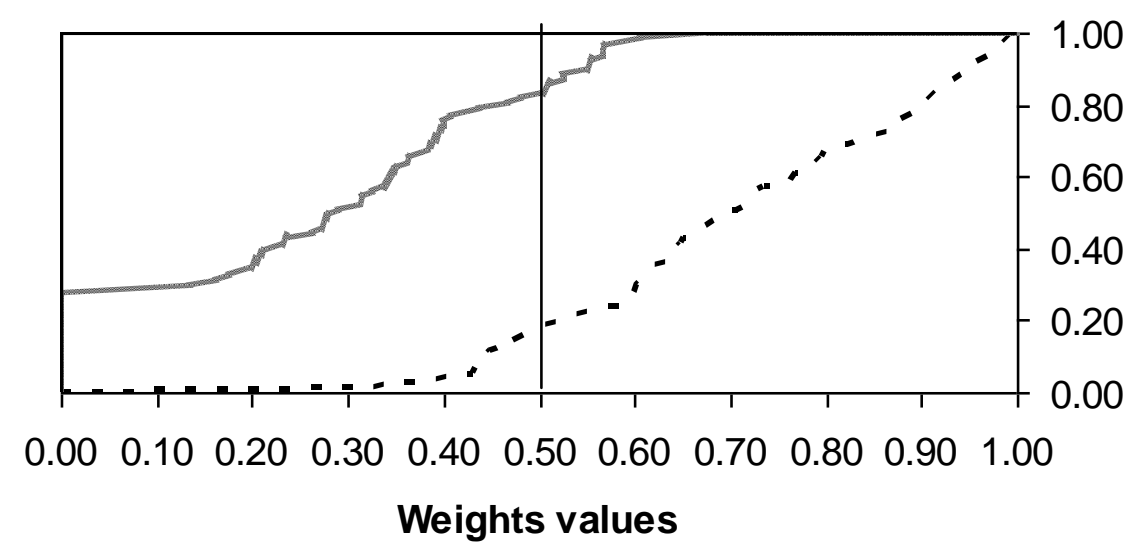

Figure 6. Probability distributions of the weights $\left(\lambda_{i}\right)$ using modified DEA model

\section{TABLES}

Table 1. Observed values of objectives in farmers sample, Example 2

\begin{tabular}{|c|c|c|c||}
\hline & TGM $(€ /$ ha) & $V A R\left(\epsilon^{2} /\right.$ ha $)$ & TL (hours/ha) \\
\hline Farmer 1 & 1250.04 & 48000.36 & 40.90 \\
\hline Farmer 2 & 1126.68 & 31014.10 & 33.06 \\
\hline Farmer 3 & 1178.94 & 31205.82 & 35.39 \\
\hline Farmer 4 & 1044.18 & 30253.43 & 33.49 \\
\hline
\end{tabular}

Table 2. Payoff matrix, Example 2 
Cite as: André, F.J., Herrero, I., Riesgo, L., 2010. Using a modified DEA model to estimate the importance of objectives. Omega, International Journal of Management Science, vol. 38: 371-382. DOI:10.1016/j.omega.2009.10.002.

http://www.sciencedirect.com/science/article/pii/S0305048309000711

\begin{tabular}{|c|c|c|c|}
\hline & MaxTGM & Min $V A R$ & $\operatorname{Min} T L$ \\
\hline TGM & 1302.71 & 486.770 & 474.89 \\
\hline$V A$ & 54857.55 & 5424.57 & 5754.11 \\
\hline$T L$ & 40.90 & 9.53 & 9.22 \\
\hline
\end{tabular}

Table 3. Estimated weights for farmers using Sumpsi et al., Example 2

\begin{tabular}{|c|c|c|c||}
\hline Farmers & $\mathrm{w}_{1}(\mathrm{TGM})$ & $\mathrm{w}_{2}(\mathrm{VAR})$ & $\mathrm{w}_{3}(\mathrm{TL})$ \\
\hline 1 & 0.985 & 0.000 & 0.015 \\
\hline 2 & 0.673 & 0.327 & 0.000 \\
\hline 3 & 0.700 & 0.300 & 0.000 \\
\hline 4 & 0.649 & 0.351 & 0.000 \\
\hline
\end{tabular}

Table 4. Estimated weights for farmers using Modified DEA, Example 2

\begin{tabular}{||c|c|c|c||}
\hline Farmers & $\lambda_{1}(\mathrm{TGM})$ & $\lambda_{2}(\mathrm{VAR})$ & $\lambda_{3}(\mathrm{TL})$ \\
\hline 1 & 0.8613 & 0.1387 & 0 \\
\hline 2 & 0.5177 & 0.4823 & 0 \\
\hline 3 & 0.5215 & 0.4785 & 0 \\
\hline 4 & 0.5023 & 0.4977 & 0 \\
\hline
\end{tabular}

Table 5. Basic features of three methods

\begin{tabular}{|c|c|c|c|c|c|c|}
\hline & \multicolumn{3}{|c|}{ Required information } & \multicolumn{2}{c|}{ Provided information } & \multirow{2}{*}{$\begin{array}{c}\text { Projection } \\
\text { criterion }\end{array}$} \\
\cline { 2 - 7 } & $\begin{array}{c}\text { Observed } \\
\text { point }\end{array}$ & $\begin{array}{c}\text { Payoff } \\
\text { matrix }\end{array}$ & Sample & $\begin{array}{c}\text { Preference } \\
\text { weights }\end{array}$ & Efficiency & Min distance \\
\hline Sumpsi & $\mathbf{X}$ & $\mathbf{X}$ & & $\mathbf{X}$ & $\mathbf{X}$ & Radial \\
\hline DEA & $\mathbf{X}$ & & $\mathbf{X}$ & & $\mathbf{X}$ & Radial \\
\hline M. DEA & $\mathbf{X}$ & $\mathbf{X}$ & & $\mathbf{X}$ & $\mathbf{X}$ & \\
\hline
\end{tabular}


Cite as: André, F.J., Herrero, I., Riesgo, L., 2010. Using a modified DEA model to estimate the importance of objectives. Omega, International Journal of Management Science, vol. 38: 371-382. DOI:10.1016/j.omega.2009.10.002.

http://www.sciencedirect.com/science/article/pii/S0305048309000711

Table 6. Statistical data on the Sumpsi et al. and modified DEA model weights

\begin{tabular}{||l|l|c|c|c|c|c|c||}
\hline & Weights & Mean & Variance & Maximum & Minimum & Median & Mode \\
\hline Sumpsi et & TGM & 0.681 & 0.027 & 0.928 & 0.328 & 0.689 & 0.928 \\
al. & VAR & 0.294 & 0.037 & 0.672 & 0 & 0.311 & 0 \\
& TL & 0.025 & 0.004 & 0.268 & 0 & 0 & 0 \\
\hline Modified & TGM & 0.729 & 0.042 & 1 & 0.321 & 0.709 & 1 \\
DEA & VAR & 0.271 & 0.042 & 0.679 & 0 & 0.291 & 0 \\
approach & TL & 0 & 0 & 0 & 0 & 0 & 0 \\
\hline \hline \multicolumn{1}{|l}{$\begin{array}{l}\text { Mean of the absolute deviation of the weights obtained by both } \\
\text { methodologies }\end{array}$} & & VAR & 0.051 \\
\end{tabular}

Table 7. Validation using weights estimated by the modified DEA method

\begin{tabular}{|c|c|c|c|c|}
\hline OBJECTIVES & $\begin{array}{c}\text { Average observed } \\
\text { values }\end{array}$ & $\begin{array}{c}\text { Average predicted } \\
\text { values }\end{array}$ & $\begin{array}{l}\text { Average } \\
\text { deviation }\end{array}$ & $\begin{array}{c}\text { Deviation } \\
(\%)\end{array}$ \\
\hline TGM (€/ha·year) & $1,170.90$ & $1,068.94$ & 169.21 & 12.60 \\
\hline VAR ( $€^{2} /$ ha.year $)$ & $36,302.01$ & $34,511.56$ & $8,705.02$ & 27.85 \\
\hline TL (hours/ha·year) & 35.77 & 31,77 & 4.99 & 15.73 \\
\hline $\begin{array}{l}\text { Decision } \\
\text { Variables (ha) }\end{array}$ & $\begin{array}{c}\text { Average observed } \\
\text { crop mix }\end{array}$ & $\begin{array}{c}\text { Average predicted } \\
\text { crop mix }\end{array}$ & \multicolumn{2}{|c|}{ Deviation (ha) } \\
\hline Wheat & 6.30 & 16.25 & \multicolumn{2}{|c|}{13.22} \\
\hline Maize & 82.59 & 69.51 & \multicolumn{2}{|c|}{15.54} \\
\hline Beans & 7.08 & 8.55 & \multicolumn{2}{|c|}{7.47} \\
\hline Set-aside & 4.18 & 5.70 & \multicolumn{2}{|c|}{6.15} \\
\hline
\end{tabular}


Cite as: André, F.J., Herrero, I., Riesgo, L., 2010. Using a modified DEA model to estimate the importance of objectives. Omega, International Journal of Management Science, vol. 38: 371-382. DOI:10.1016/j.omega.2009.10.002.

http://www.sciencedirect.com/science/article/pii/S0305048309000711

Table 8. Comparing standard DEA and modified DEA models in order to measure efficiency

\begin{tabular}{|c|c|c|c|}
\hline & $\begin{array}{c}\bar{\xi}_{\mathrm{i}} \text { (truncated) } \\
\text { perturbation }\end{array}$ & $\begin{array}{c}\text { Efficiency measure } \\
\text { Standard DEA }\end{array}$ & $\begin{array}{c}\text { Efficiency measure } \\
\text { Modified DEA }\end{array}$ \\
\hline Mean & 0.913 & 0.907 & 0.950 \\
\hline Standard Error & 0.085 & 0.083 & 0.075 \\
\hline Correlation with $\bar{\xi}_{\mathrm{i}}$ & 1.000 & 0.974 & 0.827 \\
\hline $\begin{array}{c}\text { Correlation with (standard) } \\
\text { DEA }\end{array}$ & 0.974 & 1.000 & 0.832 \\
\hline
\end{tabular}

